\title{
Heavy Metals Removal from Aqueous Solution by Modified Natural Zeolites Using Central Composite Design
}

\author{
Monireh Rahimi', Jafar Mahmoudi1* \\ 1 School of Chemistry, Damghan University, University Street, University Square, 36716-41167 Damghan, Iran \\ *Corresponding author, e-mail: mahmoudi@du.ac.ir
}

Received: 06 September 2018, Accepted: 27 February 2019, Published online: 27 May 2019

\begin{abstract}
Removal of heavy metals including $\mathrm{Pb}, \mathrm{Co}, \mathrm{Cr}$ and $\mathrm{Zn}$ from an aqueous solution was investigated using modified clinoptilolite zeolites as adsorbents. The adsorbents were characterized by X-ray, FTIR, SEM and BET. The central composite design defined under response surface methodology was applied for design of experiments. According to the results, clinoptilolite/MgO showed higher capacity for absorption of lead $(98.38 \%$ ) in comparison to clinoptilolite/ $\mathrm{NaOH}$. The removal percentage of $\mathrm{Co}, \mathrm{Cr}$ and $\mathrm{Zn}$ was obtained $89.51 \%$, $81.07 \%$ and $78.24 \%$, respectively, using clinoptilolite/MgO. Moreover, the equilibrium experimental data well fitted the Freundlich isotherm model, as compared with the Langmuir isotherm. The results show that the complete regeneration of adsorbents can be achieved at room temperature using $\mathrm{NaCl}(0.35 \mathrm{M})$.
\end{abstract}

Keywords

heavy metal, clinoptilolite zeolite, $\mathrm{NaOH}, \mathrm{MgO}$, response surface methodology

\section{Introduction}

Recently, environmental pollution by hazardous materials including heavy metals has attracted the attention of scientists. With the development of various industries, significant amounts of heavy metals with industrial waste have been discharged into the environment, thus endangering the human health [1-2]. Because of their high degree of toxicity, arsenic, lead, mercury, cadmium and chromium are considered as toxic and extremely dangerous, even at trace levels [3-7]. There are several methods to remove heavy metals from water or wastewater such as chemical settling, flocculation, ion exchange, membrane processes, evaporation and adsorption [8]. Among them, adsorption is known today as an effective and economic method for wastewater treatment from heavy metals. In the adsorption process, the adsorbent plays an important role in the removal of heavy metals, clay mineral, bioadsorbent, industrial by-products, fly ash, coal, chitosan and zeolite are used as low-cost adsorbents. Since zeolites are the cheapest and most readily available adsorbents, they are most frequently used in comparing to the other mentioned low-cost absorbents [9]. Zeolite is hydrated crystalline aluminosilicate made up of three-dimensional structure and tetrahedral alumina $\left(\mathrm{AlO}_{4}\right)$ and silica $\left(\mathrm{SiO}_{4}\right)$ [10-12].
Clinoptilolite is one of the useful natural zeolites due to its high absorption rate, cation exchange, catalysis and dehydration capacities. Some research has shown that clinoptilolite zeolite has a high selectivity relative to some heavy metal ions such as copper, lead and cadmium [13, 14]. In addition to adsorbents, other parameters such as heavy metal ion concentration, temperature, $\mathrm{pH}$ and time affect the removal of heavy metals from water and wastewater. To investigate the effects of various variables simultaneously, the use of an appropriate design of experiment (DOE) method is required. One of the useful methods for design of experiments, statistical modeling and process optimization is response surface methodology (RSM) $[15,16]$.

In this work, the removal of heavy metals from an aqueous solution was investigated by an adsorption process over clinoptilolite zeolite and clinoptilolite zeolite modified with $\mathrm{NaOH}$ and $\mathrm{MgO}$. The influences of effective parameters including heavy metal ion concentration in aqueous solution, temperature, contact time and adsorbent dosage were simultaneously investigated for removal percentage of heavy metals including lead, cobalt, chromium and zinc over the modified clinoptilolite zeolite by designing an experiment using the RSM. 
The optimum conditions for removal of heavy metals were obtained. Moreover, experimental data were analyzed by the Langmuir and Freundlich isotherm models to describe the adsorption process as a function of equilibrium concentration.

\section{Exprimental}

\subsection{Materials}

Sodium hydroxide $(\mathrm{NaOH})$, magnesium oxide $(\mathrm{MgO})$ and acetic acid $\left(\mathrm{CH}_{3} \mathrm{COOH}\right)$ were used for the modifying adsorbent. All these chemicals were obtained from Merck, Iran. Moreover, clinoptilolite zeolite was obtained from the Semnan area, Iran.

\subsection{Preparation of the adsorbent}

\subsubsection{The modified zeolite with $\mathrm{NaOH}$}

The clinoptilolite zeolite was washed with deionized water and then dried at $120{ }^{\circ} \mathrm{C}$ for $24 \mathrm{~h}$. Afterwards, $10 \mathrm{~g}$ of the washed zeolite was mixed with $250 \mathrm{ml}$ of sodium hydroxide $(\mathrm{NaOH}) 1 \mathrm{M}$ by reflux at $90{ }^{\circ} \mathrm{C}$ for 90 min with stirring speed of $300 \mathrm{rpm}$.

\subsubsection{The modified zeolite with $\mathrm{MgO}$}

At this step, $2 \mathrm{~g}$ of the washed zeolite was mixed with $30 \mathrm{ml}$ of acetic acid for $1 \mathrm{~h}$ with stirring speed of $250 \mathrm{rpm}$ and then dried at $170{ }^{\circ} \mathrm{C}$ for $24 \mathrm{~h}$. The weight ratio of $4: 1$ of acidified zeolite and magnesium oxide were mixed and then calcined at $400{ }^{\circ} \mathrm{C}$ for $4 \mathrm{~h}$.

\subsection{Characterization of the adsorbent}

$\mathrm{X}$-ray diffractometer (D8-Advance, Bruker AXS, Cu $\mathrm{K} \alpha, \lambda=1.54^{\circ} \mathrm{A}$ ) was used to determine the structure of the synthesized adsorbents.

The infrared spectra of the adsorbents were recorded using Perkin Elmer Spectrum RXI FT-IR in the range of 4000 to $400 \mathrm{~cm}^{-1}$. The solid samples were mixed with $\mathrm{KBr}$ powder and compressed into pellet for analysis.

Scanning electron microscopy (SEM) (JEOL, JSM $6490 \mathrm{LV}$ ) was used for determining the morphology of the non-modified and modified clinoptilolite zeolite with electron acceleration voltage of $20 \mathrm{kV}$.

Surface area and pore size of the adsorbents were measured using the nitrogen adsorption-desorption method (by ASAP 2010 instrument) at liquid nitrogen temperature $\left(-196{ }^{\circ} \mathrm{C}\right)$. Prior to the measurements, the sample was degassed at $300{ }^{\circ} \mathrm{C}$ under vacuum for $6 \mathrm{~h}$.

\subsection{Heavy metal adsorption}

For the adsorption of metals, $\mathrm{Pb}\left(\mathrm{NO}_{3}\right)_{2}, \mathrm{Co}\left(\mathrm{NO}_{3}\right)_{2}$, $\mathrm{Cr}\left(\mathrm{NO}_{3}\right)_{2}$ and $\mathrm{ZnSO}_{4}$ hydrated salts were used for preparation of aqueous solutions containing different concentrations of metal ions. The experiment conditions are shown in Table 1. First, the determined amount of the adsorbent was activated at $120{ }^{\circ} \mathrm{C}$ in oven for $2 \mathrm{~h}$ and then cooled to ambient temperature. Subsequently, the adsorbent was mixed with $10 \mathrm{~mL}$ of an aqueous solution of metal ions with determined concentration and temperature. The mixture was shaken at a constant agitation speed (250 rpm) for a determined contact time. After the contact time, the process was stopped and the products were withdrawn from the vessel and centrifuged at $3600 \mathrm{rpm}$ for $30 \mathrm{~min}$ to separate the remaining adsorbent. In these experiments, $\mathrm{pH}$ of initial solutions before addition of adsorbent were determined 4.7-4.3 for solutions at concentration of 300$1500 \mathrm{mg} / \mathrm{L}$ respectively. The concentrations of metal ions in the solutions before and after adsorption were determined using atomic absorption spectroscopy (Chemtech analytical CTA-2000). All the results were expressed as averaged values of duplicate tests. The adsorption capacity $\left(q_{e}\right)$ and removal percentage $(R, \%)$ were calculated using the Eq. (1) and Eq. (2), respectively [14, 17]:

$$
\begin{aligned}
& q_{e}=\frac{m\left(C_{0}-C_{e}\right)}{V} \\
& R(\%)=\frac{\left(C_{0}-C_{e}\right)}{C_{0}} \times 100
\end{aligned}
$$

where $q_{e}(\mathrm{mg} / \mathrm{g})$ is the adsorption capacity for metal ions at equilibrium, $\mathrm{C}_{0}(\mathrm{mg} / \mathrm{L})$ is the initial concentrations of heavy metal ions in the solution, $C_{e}(\mathrm{mg} / \mathrm{L})$ is the equilibrium concentration of heavy metal ions remained in the solution, $V(\mathrm{~L})$ is the volume of the solution and $m(\mathrm{~g})$ is the amount of the adsorbent. In this research, first, the optimum condition of the adsorption of lead from the aqueous solution using clinoptilolite zeolite modified with $\mathrm{NaOH}$ was obtained by designing an experiment using the RSM. Then, at the obtained optimum condition, the adsorption of lead from the aqueous solution using $\mathrm{MgO} /$ clinoptilolite zeolite was performed. Finally, the adsorption of other metal ions such as chromium, cobalt and zinc was performed by $\mathrm{MgO} /$ clinoptilolite zeolite. Table 1 shows the experimental conditions for adsorption of lead from the aqueous solution over $\mathrm{NaOH} /$ clinoptilolite zeolite. 
Table 1 Lead concentrations, temperature, contact time and adsorbent dosage in adsorption experiment using $\mathrm{NaOH} / \mathrm{Clinoptilolite} \mathrm{zeolite.}$

\begin{tabular}{lccccc}
\hline $\begin{array}{l}\mathrm{Pb}^{2+} \text { concentration } \\
(\mathrm{mg} / \mathrm{L})\end{array}$ & 300 & 600 & 900 & 1200 & 1500 \\
\hline Temperature $\left({ }^{\circ} \mathrm{C}\right)$ & 17.50 & 25 & 32.50 & 40 & 47.50 \\
Contact time (min) & 5 & 20 & 35 & 50 & 65 \\
Dosage of adsorbent $(\mathrm{gr} / \mathrm{L})$ & 2 & 8 & 14 & 20 & 26 \\
\hline
\end{tabular}

\subsection{Regeneration of adsorbents}

$1 \mathrm{gr}$ of adsorbent was mixed with $100 \mathrm{ml}$ of an aqueous solution of metal ion at a concentration of $300 \mathrm{mg} / \mathrm{L}$. The mixture was shaken at a constant agitation speed for $6 \mathrm{~h}$. then the process was stopped and the solution was filtered to separate the adsorbent from solution and the filtrate was analyzed in AAS for its metal ion content.

Also the solid matters with adsorbed heavy metal were washed with deionized water and dried at $100{ }^{\circ} \mathrm{C}$ for $20 \mathrm{~h}$. Then the adsorbent was placed into the $100 \mathrm{ml}$ of $\mathrm{NaCl}$ at the concentration of $0.35 \mathrm{M}$ and desorption experiment were performed for 6 hours under suitable stirring. Then the solution was filtered and the adsorbent was separated; the filtrate was analyzed for its metal ion content.

\subsection{Experimental design using the response surface methodology (RSM)}

In this research, the central composite design (CCD) was selected to study the combined influences of the parameters and process optimization. The studied parameters consisted of $\mathrm{Pb}^{2+}$ concentration (in range of 300$1500 \mathrm{mg} / \mathrm{L}$ ), temperature (in range of $17.50-47.50{ }^{\circ} \mathrm{C}$ ), contact time (in range of 5-65 $\mathrm{min}$ ) and dosage of adsorbent (in range of 2-26 g/L). This design examined the influences of 4 factors in 2 levels (high +1 and low -1). The axial points were located at $( \pm \alpha, 0,0),(0, \pm \alpha, 0)$ and $(0,0, \pm \alpha)$, where $\alpha$ equaled 2 . The software provided 27 experiments at different conditions with three border points. In this research, the design of the experiments was done by Design Expert version 7.0.0.

\section{Results and discussion}

\subsection{Characterization of the adsorbent}

Fig. 1 shows FTIR spectra of clinoptilolite zeolite and the modified clinoptilolite zeolite with $\mathrm{NaOH}$ and $\mathrm{MgO}$, respectively. The spectra in the range of $400-800 \mathrm{~cm}^{-1}$ represented the symmetric stretching vibration [18] that decreased in the modified zeolites due to decationization from of clinoptilolite zeolite $[19,20]$. The strong spectrum around $1047 \mathrm{~cm}^{-1}$ was stretching vibration $\mathrm{Si}-(\mathrm{Al})-\mathrm{O}$ in

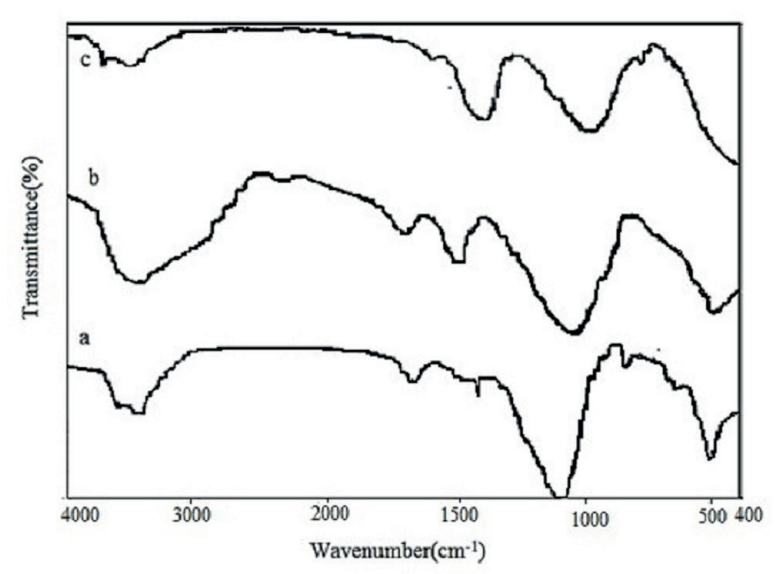

Fig. 1 FTIR spectra: (a) clinoptilolite zeolite, (b) $\mathrm{NaOH} /$ clinoptilolite zeolite and (c) $\mathrm{MgO} /$ clinoptilolite zeolite.

tetrahedral $\mathrm{Si}(\mathrm{Al}) \mathrm{O}_{4}[21]$. The band appeared at $1300 \mathrm{~cm}^{-1}$ was related to the asymmetric stretching vibration Al-O or Si-O in clinoptilolite zeolite [19]. The spectrum at $1300 \mathrm{~cm}^{-1}$ that increased in the modified $\mathrm{NaOH} /$ clinoptilolite zeolite comparing with clinoptilolite zeolite, indicated the presence of aluminum on the surface and desilication in the $\mathrm{NaOH} / \mathrm{clinoptilolite} \mathrm{zeolite} \mathrm{[22].} \mathrm{As} \mathrm{seen} \mathrm{in} \mathrm{Fig.} 1$ (c), the displacement of the band can confirm the $\mathrm{MgO}$ influence on the clinoptilolite zeolite. Moreover, the bands observed at 1429 and $1640 \mathrm{~cm}^{-1}$ were assigned to $\mathrm{MgO}$ and $\mathrm{COO}$-, respectively. The broad spectrum in the range of 3400$3600 \mathrm{~cm}^{-1}$ was assigned to hydroxyl groups. In Fig. 1 (b), this band increased due to increasing the ratio of $\mathrm{Al}$ to $\mathrm{Si}$ and increasing $\mathrm{OH}$ in the modified zeolite with $\mathrm{NaOH}$ [20, 21].

The structure of the various synthesized samples was identified with XRD in from $2 \theta=4^{\circ}$ to $2 \theta=70^{\circ}$ (Fig. 2). Clinoptilolite zeolite had several characteristic peaks at $2 \Theta=9.63^{\circ}, 22.40^{\circ}, 26.71^{\circ}, 30.19^{\circ}$ and $32.74^{\circ}$, which were assigned to biotite, clinoptilolite, quartz, feldspar and dolomite, respectively [20, 21]. For the $\mathrm{NaOH} /$ clinoptilolite zeolite sample, the intensity of the characteristic peaks of clinoptilolite zeolite had an overall decrease. Moreover, the intensity of the peak at $2 \Theta=35^{\circ}$ increased due to the entering of the hydroxyl group of $\mathrm{NaOH}$ into the sodalite cavity of clinoptilolite zeolite [20,22]. Moreover, it was observed in Fig. 2 (c) that the peak intensity of $\mathrm{MgO} /$ clinoptilolite zeolite decreased, as compared with that of clinoptilolite zeolite. The characteristic peaks of $\mathrm{MgO}$ appeared in $2 \Theta=42.91^{\circ}$ and $62.32^{\circ}$, indicating the presence of $\mathrm{MgO}$ in the pores of the zeolite [23].

The SEM micrographs of the synthesized samples are shownin Fig. 3. The results showed that the surface of clinoptilolite zeolite was unruly and its porosity was low [24]. 


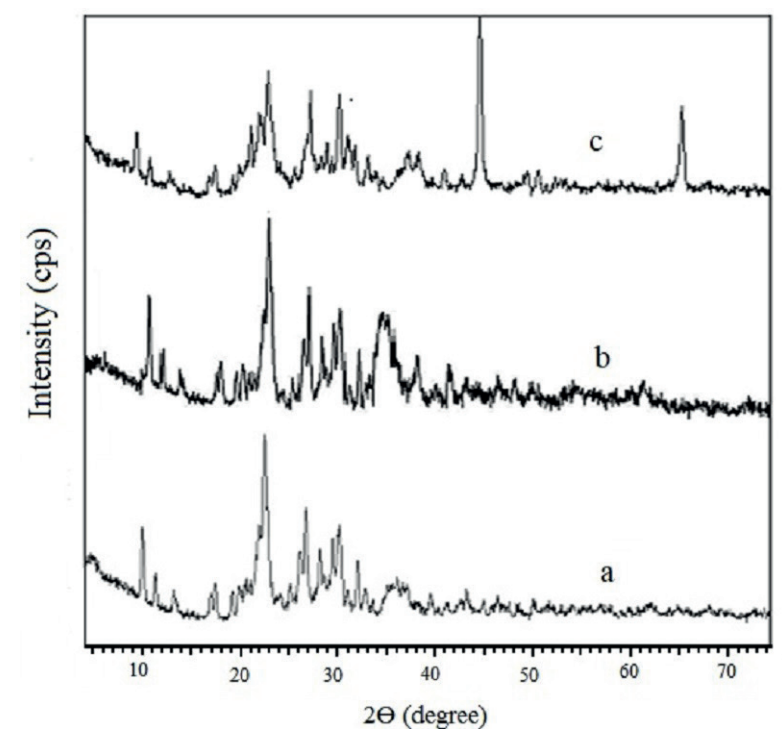

Fig. 2 XRD patterns: (a) clinoptilolite zeolite, (b) $\mathrm{NaOH} /$ clinoptilolite zeolite and (c) $\mathrm{MgO} /$ clinoptilolite zeolite

In the $\mathrm{NaOH} /$ clinoptilolite zeolite sample, the particles were accumulated, causing to increase the porosity of this sample. As can be seen in Fig. 3 (c), the formation of clinoptilolite zeolite/MgO sheet structure was confirmed by SEM. The porosity of this sample was higher than that of the other samples [14].

Specific surface areas of the samples were determined using the BET equation and pore size were estimated by Barrett-Joyner-Halenda (BJH) method. The specific surface area and pore size of the studied adsorbents are presented in Table 2. Based on Table 2 the surface area of the adsorbents modified by $\mathrm{NaOH}$ and $\mathrm{MgO}$ were decreased which attributed to desilication and dealumination of Clinoptilolite zeolite. Furthermore, the pore diameters of modified samples were increased in compared to the Clinoptilolite zeolite. The pore diameter is very important parameters affected the amount of adsorbate molecules that transported into the surface inside of particles. The observed results were in good agreement with the reported values [20].

Table 2 Surface area and pore size of the clinoptilolite zeolite and modified adsorbents

\begin{tabular}{lcc}
\hline Adsorbent & $\begin{array}{c}\text { BET-surface } \\
\text { area }\left(\mathrm{m}^{2} / \mathrm{g}\right)\end{array}$ & $\begin{array}{c}\text { Pore diameter } \\
(\AA)\end{array}$ \\
\hline Clinoptilolite zeolite & 95.7 & 145.8 \\
$\mathrm{NaOH} /$ Clinoptilolite & 61.9 & 209.1 \\
$\mathrm{MgO} / \mathrm{Clinoptilolite}$ & 78.4 & 263.5 \\
\hline
\end{tabular}
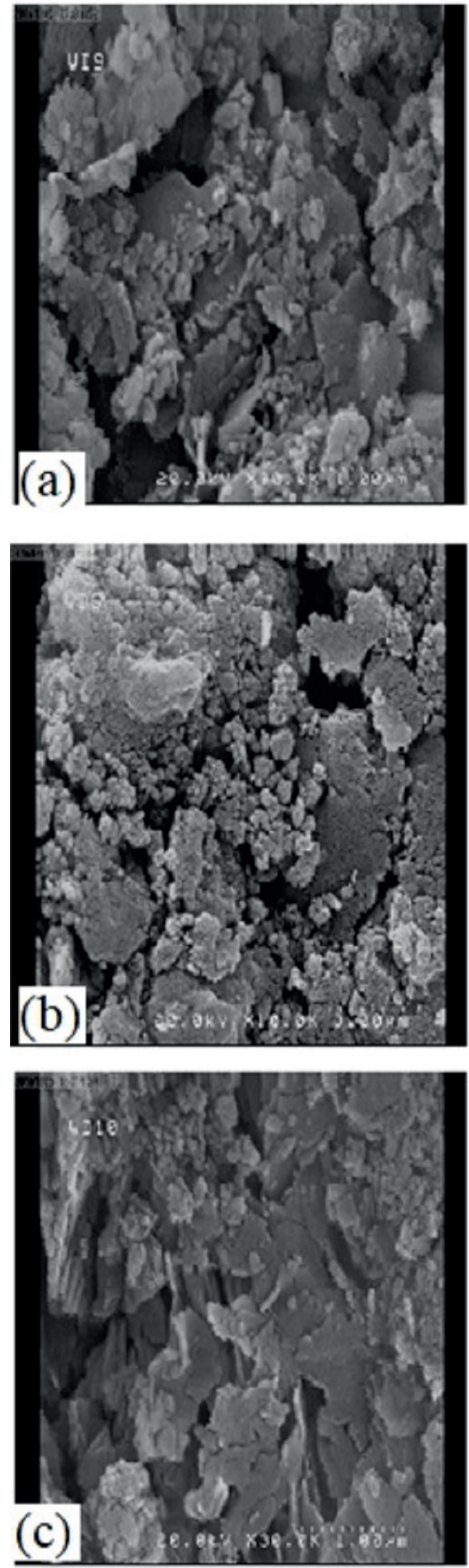

Fig. 3 SEM images: (a) clinoptilolite zeolite, (b) $\mathrm{NaOH} /$ clinoptilolite zeolite and (c) $\mathrm{MgO} /$ clinoptilolite zeolite. 


\subsection{Adsorption of lead from the aqueous solution}

Table 3 shows experimental conditions and results of removal of lead from the aqueous solution by $\mathrm{NaOH} / \mathrm{clinop}-$ tilolite zeolite. The relationship between effective variables, i.e. temperature, contact time, initial concentrations of lead in the solution and zeolite dosage, and the removal percentage of lead from the aqueous solution was analyzed.

The analysis of variance (ANOVA) for response surface reduced quadratic model is presented in Table 4. The model F-value was obtained 6.58, showing that the model was significant. Values of "Prob $>F$ " less than 0.0500 indicated that the model terms were significant whereas values greater than 0.1000 indicated that the model terms were not significant. According to F-values and the importance of parameters (initial concentration (A), temperature (B), contact time (C) and dosage adsorbent (D)), the following was observed: $\mathrm{D}^{2}>\mathrm{C}^{2}>\mathrm{B}^{2}>\mathrm{A}^{2}$ that were significant model terms.

The $\mathrm{R}^{2}$ value equal to 0.8763 showed that there was good agreement between the experimental data and predicted data. The predicted $\mathrm{R}^{2}$ value of 0.8735 agreed with the adjusted $\mathrm{R}^{2}$ of 0.7430 reasonably. Also the effect estimates of all terms are presented in Table 5. Based on Table 5, coefficient estimate specified the size and the positive or negative effect of the each parameters on the response. The equation of response comes from coefficient estimate. Equation (3) is a modified equation to predict the removal of lead.

$$
\begin{aligned}
R & =1.53 \times A-0.12 \times B-0.32 \times C+0.46 \times D \\
& -1.04 \times A \times B+0.24 \times A \times C-0.46 \times A \times D \\
& +0.34 \times B \times C+0.2 \times B \times D+0.043 \times C \times D \\
& +19.13 \times A^{2}+19.65 \times B^{2}+20.21 \times C^{2}+20.22 \times D^{2} .
\end{aligned}
$$

\begin{tabular}{|c|c|c|c|c|c|c|c|c|c|}
\hline \multirow[b]{2}{*}{ Run } & & & & & \multicolumn{4}{|c|}{ Adsorption operating parameters } & \multirow{2}{*}{$\begin{array}{c}\text { Response } \\
\text { Removal percentage } \\
(\%)\end{array}$} \\
\hline & \multicolumn{4}{|c|}{ Levels } & $\begin{array}{c}\text { Initial concentration } \\
(\mathrm{ppm})\end{array}$ & $\begin{array}{c}\text { Temperature } \\
\left({ }^{\circ} \mathrm{C}\right)\end{array}$ & $\begin{array}{l}\text { Time } \\
(\mathrm{min})\end{array}$ & $\begin{array}{l}\text { Zeolite dosage } \\
(\mathrm{g} / \mathrm{L})\end{array}$ & \\
\hline 1 & -1 & -1 & -1 & -1 & 600.00 & 25.00 & 20.00 & 8.00 & 75.57 \\
\hline 2 & +1 & -1 & -1 & -1 & 1200.00 & 25.00 & 20.00 & 8.00 & 83.14 \\
\hline 3 & -1 & +1 & +1 & -1 & 600.00 & 40.00 & 20.00 & 8.00 & 78.34 \\
\hline 4 & +1 & +1 & -1 & -1 & 1200.00 & 40.00 & 20.00 & 8.00 & 75.08 \\
\hline 5 & -1 & -1 & +1 & -1 & 600.00 & 25.00 & 50.00 & 8.00 & 73.24 \\
\hline 6 & +1 & -1 & +1 & -1 & 1200.00 & 25.00 & 50.00 & 8.00 & 78.16 \\
\hline 7 & -1 & +1 & +1 & -1 & 600.00 & 40.00 & 50.00 & 8.00 & 74.40 \\
\hline 8 & +1 & +1 & +1 & -1 & 1200.00 & 40.00 & 50.00 & 8.00 & 80.72 \\
\hline 9 & -1 & -1 & -1 & +1 & 600.00 & 25.00 & 20.00 & 20.00 & 76.12 \\
\hline 10 & +1 & -1 & -1 & +1 & 1200.00 & 25.00 & 20.00 & 20.00 & 81.99 \\
\hline 11 & -1 & +1 & -1 & +1 & 600.00 & 40.00 & 20.00 & 20.00 & 80.50 \\
\hline 12 & +1 & +1 & -1 & +1 & 1200.00 & 40.00 & 20.00 & 20.00 & 80.21 \\
\hline 13 & -1 & -1 & +1 & +1 & 600.00 & 25.00 & 50.00 & 20.00 & 77.83 \\
\hline 14 & +1 & -1 & +1 & +1 & 1200.00 & 25.00 & 50.00 & 20.00 & 79.61 \\
\hline 15 & -1 & +1 & +1 & +1 & 600.00 & 40.00 & 50.00 & 20.00 & 77.84 \\
\hline 16 & +1 & +1 & +1 & +1 & 1200.00 & 40.00 & 50.00 & 20.00 & 78.62 \\
\hline 17 & -2 & 0 & 0 & 0 & 300.00 & 32.50 & 35.00 & 14.00 & 75.19 \\
\hline 18 & +2 & 0 & 0 & 0 & 1500.00 & 32.50 & 35.00 & 14.00 & 81.76 \\
\hline 19 & 0 & -2 & 0 & 0 & 900.00 & 17.50 & 35.00 & 14.00 & 81.33 \\
\hline 20 & 0 & +2 & 0 & 0 & 900.00 & 47.50 & 35.00 & 14.00 & 79.81 \\
\hline 21 & 0 & 0 & -2 & 0 & 900.00 & 32.50 & 5.00 & 14.00 & 82.07 \\
\hline 22 & 0 & 0 & +2 & 0 & 900.00 & 32.50 & 65.00 & 14.00 & 83.54 \\
\hline 23 & 0 & 0 & 0 & -2 & 900.00 & 32.50 & 35.00 & 2.00 & 83.62 \\
\hline 24 & 0 & 0 & 0 & +2 & 900.00 & 32.50 & 35.00 & 26.00 & 82.06 \\
\hline 25 & 0 & 0 & 0 & 0 & 900.00 & 32.50 & 35.00 & 14.00 & 84.04 \\
\hline 26 & 0 & 0 & 0 & 0 & 900.00 & 32.50 & 35.00 & 14.00 & 84.73 \\
\hline 27 & 0 & 0 & 0 & 0 & 900.00 & 32.50 & 35.00 & 14.00 & 83.23 \\
\hline
\end{tabular}

Table 3 Experimental conditions and results of CCD for removal of lead over $\mathrm{NaOH} / \mathrm{clinoptilolite}$ zeolite 
Table 4 ANOVA table for response surface reduced quadratic model for Removal percentage of lead

\begin{tabular}{|c|c|c|c|c|c|}
\hline Source & Sum of Squares & Degree of freedom (df) & Mean Square & F Value & $\mathrm{p}$-value Prob $>\mathrm{F}$ \\
\hline Model & $1.506 \mathrm{E}+005$ & 14 & 10760.71 & 6.58 & 0.0008 \\
\hline A & 56.52 & 1 & 56.52 & 0.035 & 0.8554 \\
\hline $\mathrm{B}$ & 0.37 & 1 & 0.37 & $2.277 \mathrm{E}-0.004$ & 0.9882 \\
\hline $\mathrm{C}$ & 2.40 & 1 & 2.40 & $1.467 \mathrm{E}-003$ & 0.9700 \\
\hline $\mathrm{D}$ & 5.00 & 1 & 5 & 3.054E-003 & 0.9568 \\
\hline $\mathrm{AB}$ & 17.20 & 1 & 17.20 & 0.011 & 0.9199 \\
\hline $\mathrm{AC}$ & 0.96 & 1 & 0.96 & $5.840 \mathrm{E}-004$ & 0.9811 \\
\hline $\mathrm{AD}$ & 3.43 & 1 & 3.43 & $2.098 \mathrm{E}-003$ & 0.9642 \\
\hline $\mathrm{BC}$ & 1.84 & 1 & 1.84 & $1.126 \mathrm{E}-003$ & 0.9737 \\
\hline $\mathrm{BD}$ & 0.64 & 1 & 0.64 & $3.887 \mathrm{E}-004$ & 0.9846 \\
\hline $\mathrm{CD}$ & 0.030 & 1 & 0.030 & 1.819E-005 & 0.9967 \\
\hline $\mathrm{A}^{2}$ & 14045.55 & 1 & 14045.55 & 8.58 & 0.0117 \\
\hline $\mathrm{B}^{2}$ & 14825.37 & 1 & 14825.37 & 9.06 & 0.0100 \\
\hline $\mathrm{C}^{2}$ & 15680.54 & 1 & 15680.54 & 9.06 & 0.0100 \\
\hline $\mathrm{D}^{2}$ & 15694.12 & 1 & 15694.12 & 9.58 & 0.0085 \\
\hline Residual & 21269.48 & 13 & 1636.11 & 9.59 & 0.0085 \\
\hline Lack of Fit & 21268.36 & 11 & 1933.49 & & \\
\hline Pure Error & 1.13 & 2 & 0.56 & 3429.99 & 0.0003 \\
\hline Cor Total & $1.719 \mathrm{E}+005$ & 27 & & & \\
\hline
\end{tabular}

$\mathrm{R}^{2}=0.8763, \mathrm{R}^{2}$ (adjusted) $=0.7430, \mathrm{R}^{2}$ (predicted) $=0.8735$.

Table 5 Effect estimates of parameters for response surface reduced quadratic model for Removal percentage of lead

\begin{tabular}{lccc}
\hline Factor & $\begin{array}{c}\text { Coefficient } \\
\text { estimate }\end{array}$ & $\begin{array}{c}\text { Degree of } \\
\text { freedom }(\mathrm{df})\end{array}$ & Standard error \\
\hline $\mathrm{A}$ & 1.53 & 1 & 8.26 \\
$\mathrm{~B}$ & -0.12 & 1 & 8.26 \\
$\mathrm{C}$ & -0.32 & 1 & 8.26 \\
$\mathrm{D}$ & 0.46 & 1 & 8.26 \\
$\mathrm{AB}$ & -1.04 & 1 & 10.11 \\
$\mathrm{AC}$ & 0.24 & 1 & 10.11 \\
$\mathrm{AD}$ & -0.46 & 1 & 10.11 \\
$\mathrm{BC}$ & 0.34 & 1 & 10.11 \\
$\mathrm{BD}$ & 0.20 & 1 & 10.11 \\
$\mathrm{CD}$ & 0.043 & 1 & 10.11 \\
$\mathrm{~A}^{2}$ & 19.13 & 1 & 6.53 \\
$\mathrm{~B}^{2}$ & 19.65 & 1 & 6.53 \\
$\mathrm{C}^{2}$ & 20.21 & 1 & 6.53 \\
$\mathrm{D}^{2}$ & 20.22 & 1 & 6.53 \\
\hline
\end{tabular}

The predicted values versus experimental values for the removal percentage of lead at different conditions are demonstrated in Fig. 4. This figure showed the close proximity of the predicted values with the actual data, signifying the validity of the regression model. Fig. 5 illustrates the

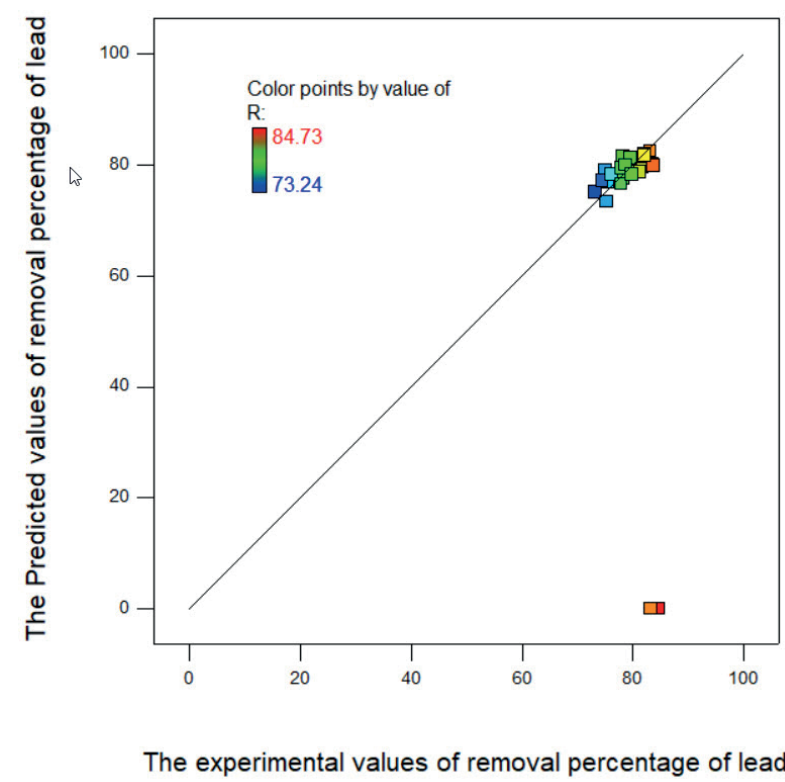

Fig. 4 Predicted versus experimental values for removal percentage of lead.

influences of temperature and initial concentration on the removal percentage of lead. As shown in the figure, increasing temperature had a negative effect on the removal percentage of lead initially and then had positive effect. For increasing of initial concentration the same trend was observed. 


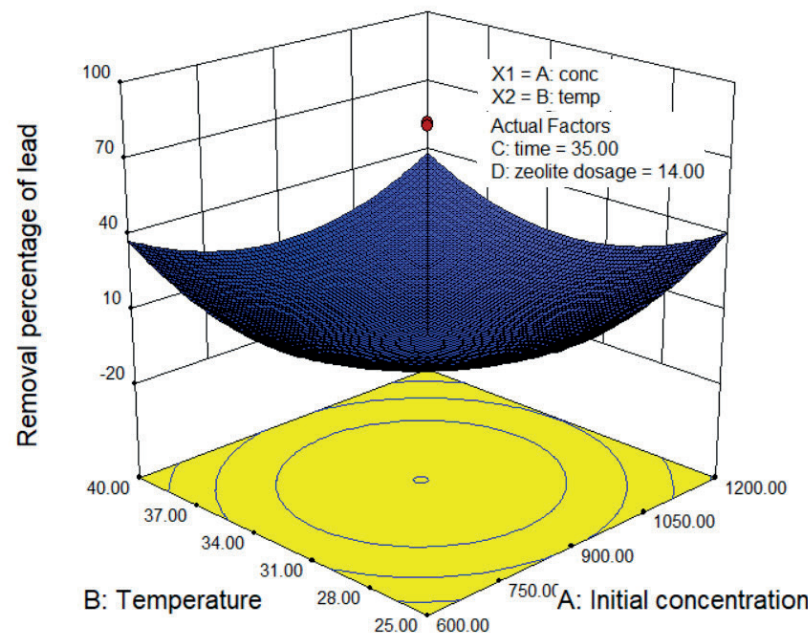

Fig. 5 Effects of temperature and initial concentration on removal percentage of lead.

The effect of the $\mathrm{pH}$ on the lead adsorption by prepared

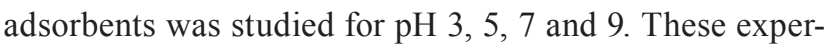
iments were carried out at the same condition for each adsorbent (initial concentration of $900 \mathrm{ppm}$, process temperature of $32.50^{\circ} \mathrm{C}$, contact time of $35 \mathrm{~min}$ and adsorption dosage of $14 \mathrm{~g} / \mathrm{L}$ ). The results were shown in Fig. 6. As can be seen in Fig. 6, the adsorption efficiency of $\mathrm{MgO}$ / clinoptilolite zeolite for all $\mathrm{pH}$ was higher than that of other adsorbents. Also for all adsorbents the removal percentage of lead increased with an increase in $\mathrm{pH}$ from 3 to 9. The low lead adsorption at acidic media has been attributed to the competition between the positively charged of $\mathrm{H}_{3} \mathrm{O}^{+}$ ions and lead ions for the available active sites on the negatively charged adsorbent surface. By increasing of $\mathrm{pH}$ and decreasing in the concentration of $\mathrm{H}_{3} \mathrm{O}^{+}$ions, the competition between two mentioned ions for surface sites would decrease and then the adsorption of lead was increased.

\subsection{Adsorption isotherm models}

The experimental data were analyzed by the Langmuir and Freundlich isotherm models [10, 25]. The Langmuir isotherm is to the monolayer adsorption and homogeneous surfaces (Eq. (4)).

$q_{e}=\frac{q_{m} K C_{e}}{1+K C_{e}}$

where $q_{m}(\mathrm{mg} / \mathrm{g})$ is the maximum amounts of adsorbate onto the adsorbent and $K(\mathrm{~L} / \mathrm{mg})$ is the Langmuir constant which represents energy of adsorption [10, 22]. In Fig. 7, $q_{m}$ and $K$ were calculated by plotting $C_{e} / q_{e}$ versus $C_{e}$.

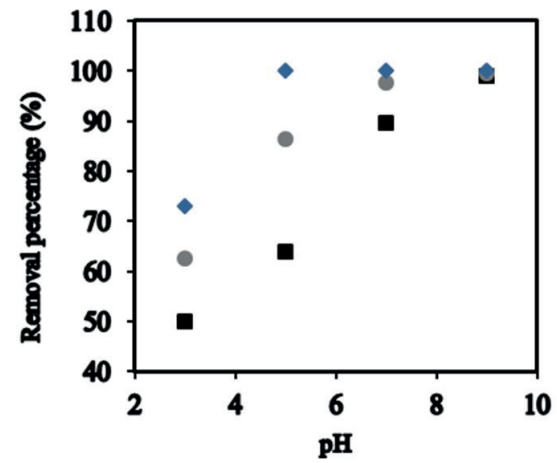

Fig. 6 Effect of $\mathrm{pH}$ on removal percentage of $\mathrm{Pb}^{2+}$; Clinoptilolite zeolite: 口; $\mathrm{NaOH} / \mathrm{Clinoptilolite} \mathrm{zeolite:} \bullet$; $\mathrm{MgO} /$ Clinoptilolite zeolite:

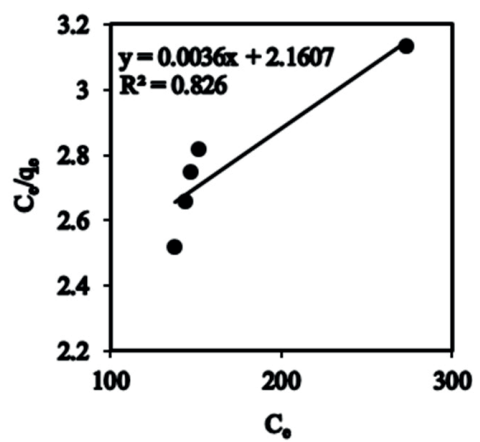

Fig. 7 Langmuir adsorption isotherm for $\mathrm{NaOH} / \mathrm{Clinoptilolite} \mathrm{zeolite.}$

The Freundlich isotherm is to the multilayer adsorption and heterogeneous surfaces (Eq. (5)).

$q_{e}=K_{f} C_{e}^{1 / n}$

The Freundlich constants are $K_{f}((\mathrm{mg} / \mathrm{g}) /(\mathrm{mg} / \mathrm{L}) 1 / \mathrm{n})$ and $1 / \mathrm{n}$ related to the adsorption capacity and adsorption intensity, respectively $[10,25]$.

Values of $\mathrm{n}$ greater than 1 imply the favorable nature of adsorption. $\mathrm{K}_{\mathrm{f}}$ and $\mathrm{n}$ are obtained from plotting $\log \left(q_{e}\right)$ versus $\log \left(C_{e}\right)$, as illustrated in Fig. 8. The parameters of these isotherm models along with their results are given in Table 6. According to the results in this table, the Freundlich model fitted the adsorption data better than the Langmuir model. Based on Table $6,1 / \mathrm{n}$ less than 1 indicated that the adsorption was desirable.

Maximum sorption capacity of $\mathrm{NaOH} /$ clinoptilolite zeolite for $\mathrm{Pb}(\mathrm{II})$ was obtained to be 258.714 (mg/g). By comparing the adsorption capacity of $\mathrm{NaOH} /$ clinoptilolite zeolite with that of Iranian bentonite $(57.803 \mathrm{mg} / \mathrm{g}$ ) [26], natural zeolite-kaolin-bentonite (140.9 mg/g) [27], and Na-Y zeolites prepared from Egyptian kaolins (260.6 meq/100 g) [28], it can be concluded that the $\mathrm{NaOH} /$ clinoptilolite 
Table 6 The Langmuir and Freundlich model

\begin{tabular}{lcc}
\hline & Langmuir Parameters & Freundlich Parameters \\
\hline$q_{m}(\mathrm{mg} / \mathrm{g})$ & 258.71 & - \\
$K_{L}(\mathrm{~L} / \mathrm{mg})$ & 0.0016 & - \\
$K_{F}((\mathrm{mg} / \mathrm{g})$ & - & 1.299 \\
$1 / \mathrm{n}$ & - & 0.749 \\
$R^{2}$ & 0.826 & 0.974 \\
\hline
\end{tabular}

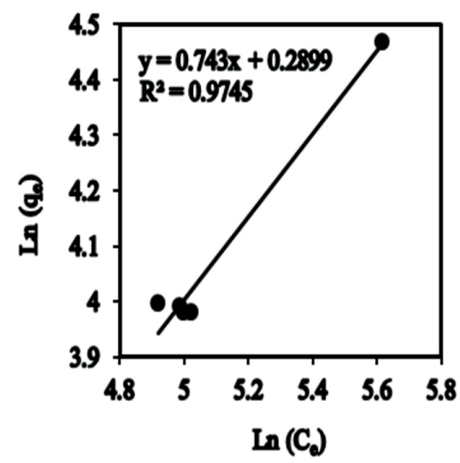

Fig. 8 Freundlich adsorption isotherm for $\mathrm{NaOH} / \mathrm{Clinoptilolite} \mathrm{zeolite.}$

zeolite efficiency in $\mathrm{Pb}$ (II) adsorption was comparable to the mentioned adsorbents.

\subsection{Adsorption of various metal ions with $\mathrm{MgO}$ / clinoptilolite zeolite}

According to the results of the experiments for the adsorption of lead using clinoptilolite zeolite modified with $\mathrm{NaOH}$, the same condition, i.e. initial concentration of $900 \mathrm{ppm}$, process temperature of $32.50{ }^{\circ} \mathrm{C}$, contact time of $35 \mathrm{~min}$ and adsorption dosage of $14 \mathrm{~g} / \mathrm{L}$, was used to analyze the performance of the modified zeolite with $\mathrm{MgO}$ as absorbent for adsorption of lead. The results are shown in Fig. 9. The Fig. 9 clearly shows that there was a significance difference in the amount of the adsorbed lead on each adsorbent at the same condition. In general, it can be concluded that the ability of $\mathrm{MgO} /$ clinoptilolite zeolite in adsorbing lead was higher than that of $\mathrm{NaOH}$ / clinoptilolite zeolite. The high ability of adsorption of $\mathrm{MgO} /$ clinoptilolite zeolite is probably due to the additional active groups from the $\mathrm{Mg}$ source on the surface of zeolite, which provide more active groups that are ready to interact with metal ions, e.g. lead.

To study the performance of $\mathrm{MgO} /$ clinoptilolite zeolite for removal of other metal ions such as chromium, cobalt and zinc, the experiments were performed at the same condition for lead removal. The results are shown in Fig. 10. According to these results, the reduction of heavy metals from the aqueous solution had the order of $\mathrm{Pb}^{2+}>$ $\mathrm{Co}^{2+}>\mathrm{Cr}^{2+}>\mathrm{Zn}^{2+}$.

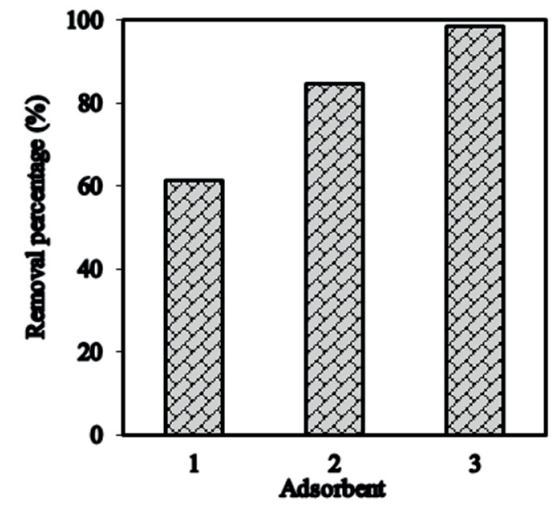

Fig. 9 Effect of adsorbent on removal percentage of $\mathrm{Pb}^{2+}$; Clinoptilolite zeolite: 1 ; $\mathrm{NaOH} / \mathrm{Clinoptilolite} \mathrm{zeolite:} 2$; MgO/Clinoptilolite zeolite: 3 .

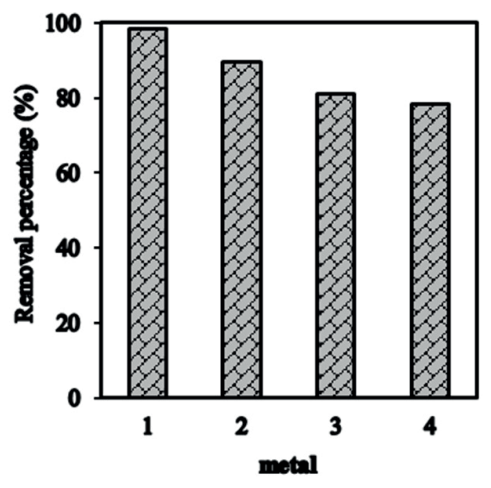

Fig. 10 The removal percentage of different heavy metal ions by $\mathrm{MgO}$ / Clinoptilolite zeolite, $\mathrm{Pb}^{2+}: 1, \mathrm{Co}^{2+}: 2, \mathrm{Cr}^{2+}: 3, \mathrm{Zn}^{2+}: 4$.

\subsection{Regeneration studies}

In this study the regeneration of adsorbents were checked using $\mathrm{NaCl}(0.35 \mathrm{M})$ for four adsorption/desorption cycles for heavy metal ions. The change in removal percentage for each adsorbent was also studied by contacting regenerated adsorbent with an aqueous solution of heavy metal ions. The results are presented in Table 7. According to these results, the removal percentages of all heavy metal ions were retained with a very slight decrease during the four adsorption/desorption cycles. This finding was in agreement with the research carried out by Katsou et al. [29].

This phenomenon could be occurred due to the replacement of the heavy metal ions and ions originally present in the mineral structure by sodium ions present in the desorbing solution that could regenerated the adsorbent and there is not significant loss in the performance of adsorbents on the regeneration cycles experiments. Moreover, the formation of complexes between chlorides and each heavy metal ions in the desorbing solution could be caused the removal of heavy metal ions from adsorbent. 
Table 7 Removal of heavy metal ions over regenerated adsorbents in four adsorption/desorption cycles.

\begin{tabular}{|c|c|c|c|}
\hline \multirow{2}{*}{$\begin{array}{l}\text { Removal } \\
\text { at cycle }\end{array}$} & \multirow{2}{*}{ Metal ion } & \multicolumn{2}{|c|}{ Adsorbent } \\
\hline & & $\mathrm{NaOH} /$ clinoptilolite & $\mathrm{MgO} /$ clinoptilolite \\
\hline 1 & \multirow{4}{*}{$\mathrm{Pb}^{2+}$} & $78.14 \%$ & $90.37 \%$ \\
\hline 2 & & $76.42 \%$ & $88.97 \%$ \\
\hline 3 & & $75.68 \%$ & $90.02 \%$ \\
\hline 4 & & $77.08 \%$ & $89.19 \%$ \\
\hline 1 & \multirow{4}{*}{$\mathrm{Co}^{2+}$} & $71.09 \%$ & $82.22 \%$ \\
\hline 2 & & $67.73 \%$ & $82.56 \%$ \\
\hline 3 & & $69.12 \%$ & $79.49 \%$ \\
\hline 4 & & $68.46 \%$ & $81.09 \%$ \\
\hline 1 & \multirow{4}{*}{$\mathrm{Cr}^{2+}$} & $64.39 \%$ & $74.46 \%$ \\
\hline 2 & & $65.01 \%$ & $73.07 \%$ \\
\hline 3 & & $62.76 \%$ & $72.38 \%$ \\
\hline 4 & & $62.09 \%$ & $71.66 \%$ \\
\hline 1 & \multirow{4}{*}{$\mathrm{Zn}^{2+}$} & $62.14 \%$ & $71.86 \%$ \\
\hline 2 & & $61.68 \%$ & $70.54 \%$ \\
\hline 3 & & $57.19 \%$ & $71.05 \%$ \\
\hline 4 & & $60.53 \%$ & $69.18 \%$ \\
\hline
\end{tabular}

metal ion concentration $=300(\mathrm{mg} / \mathrm{L}), \mathrm{pH}=4.7, \mathrm{~T}=25^{\circ} \mathrm{C}$ and $\mathrm{t}=6 \mathrm{~h}$.

\section{Conclusion}

The present study showed that clinoptilolite zeolite modified with $\mathrm{NaOH}$ and $\mathrm{MgO}$ had much potential as adsorbents for the removal of heavy metal ions from the

\section{Reference}

[1] Wang, J., Chen, C. "Biosorption of heavy metals by Saccharomyces cerevisiae: a review", Biotechnology Advances, 24(5), pp. 427451, 2006.

https://doi.org/10.1016/j.biotechadv.2006.03.001

[2] Perić, J., Trgo, M., Medvidović, N. V. "Removal of zinc, copper and lead by natural zeolite a comparison of adsorption isotherms", Water Research, 38(7), pp. 1893-1899, 2004.

https://doi.org/10.1016/j.watres.2003.12.035

[3] Farooq, U., Kozinski, J. A., Khan, M. A. Athar, M. "Biosorption of heavy metal ions using wheat based biosorbents-a review of the recent literature", Bioresource Technology, 101(14), pp. 5043-5053, 2010.

https://doi.org/10.1016/j.biortech.2010.02.030

[4] Naseem, R., Tahir, S. S. "Removal of Pb (II) from aqueous/acidic solutions by using bentonite as an adsorbent", Water Research, 35(16), pp. 3982-3986, 2001.

https://doi.org/10.1016/S0043-1354(01)00130-0

[5] Oyaro, N., Ogendi, J., Murago, E. N., Gitonga, E. "The contents of $\mathrm{Pb}, \mathrm{Cu}, \mathrm{Zn}$ and $\mathrm{Cd}$ in meat in Nairobi, Kenya", Journal of Food, Agriculture \& Environment, 5(3\&4), pp. 119-121, 2007. aqueous solution. The properties of natural and modified zeolites were studied by various techniques such as XRD, FTIR, SEM and BET. The influences of the initial concentration, contact time, temperature and amount of adsorbent on adsorption of the metal ions and their interactions were investigated by a response surface methodology and ANOVA. The results showed that the importance of parameters (initial concentration (A), temperature (B), contact time $(\mathrm{C})$ and dosage adsorbent (D)), the following was observed: $\mathrm{D}^{2}>\mathrm{C}^{2}>\mathrm{B}^{2}>\mathrm{A}^{2}$. The equilibrium data were fitted using the Freundlich and Langmuir isotherm models. The Freundlich isotherm model was more appropriate for the results obtained on $\mathrm{NaOH}$ /clinoptilolite zeolite. By comparison between $\mathrm{NaOH} /$ clinoptilolite and $\mathrm{MgO} /$ clinoptilolite, it can be concluded that the ability of $\mathrm{MgO} /$ clinoptilolite zeolite in adsorbing lead was higher than that of $\mathrm{NaOH} /$ clinoptilolite zeolite at the same conditions. The obtained results also showed that $\mathrm{MgO} /$ clinoptilolite zeolite exhibited effective adsorption for $\mathrm{Pb}^{2+}, \mathrm{Co}^{2+}, \mathrm{Cr}^{2+}$ and $\mathrm{Zn}^{2+}$ ions in the aqueous solution with removal percentage in the order $\mathrm{Pb}^{2+}>\mathrm{Co}^{2+}>\mathrm{Cr}^{2+}>\mathrm{Zn}^{2+}$.

The regenerated adsorbents were used for four adsorption experiment and the obtained results indicated that the removal percentage of all heavy metal ions is the same or changed slightly.

[6] Borba, C. E., Guirardello, R., Silva, E. A., Veit, M. T., Tavares, C. R. G. "Removal of nickel (II) ions from aqueous solution by biosorption in a fixed bed column: experimental and theoretical breakthrough curves", Biochemical Engineering Journal, 30(2), pp. 184191,2006

https://doi.org/10.1016/j.bej.2006.04.001

[7] Paulino, A. T., Minasse, F. A., Guilherme, M. R., Reis, A. V., Muniz, E. C., Nozaki, J. "Novel adsorbent based on silkworm chrysalides for removal of heavy metals from wastewaters", Journal of Colloid and Interface Science, 301(2), pp. 479-487. 2006. https://doi.org/10.1016/j.jcis.2006.05.032

[8] Wang, J., Chen, C. "Biosorbents for heavy metals removal and their future", Biotechnology Advances, 27(2), pp. 195-226, 2009. https://doi.org/10.1016/j.biotechadv.2008.11.002

[9] Babel, S., Kurniawan, T. A. "Low-cost adsorbents for heavy metals uptake from contaminated water: a review", Journal of Hazardous Materials, 97(1-3), pp. 219-243, 2003. https://doi.org/10.1016/S0304-3894(02)00263-7

[10] Erdem, E., Karapinar, N., Donat, R. "The removal of heavy metal cations by natural zeolites", Journal of Colloid and Interface Science, 280(2), pp. 309-314, 2004. https://doi.org/10.1016/j.jcis.2004.08.028 
[11] Yafei, Zh., Bing, Zh., Yanwu, Zh., Jinhua, W., Jindun, L., Rongfeng, C. "Removal of Ammonium from Wastewater by Pure Form Low-Silica Zeolite Y Synthesized from Halloysite Mineral", Separation Science and Technology, 45(8), pp. 1066-1075, 2010. https://doi.org/10.1080/01496391003696822

[12] Sahner, K., Hagen, G., Schönauer, D., Reiss, S., Moos, R. "Zeolites- Versatile materials for gas sensors", Solid State Ionics, 179(40), pp. 2416-2423, 2008. https://doi.org/10.1016/j.ssi.2008.08.012

[13] Zamzow, M. J., Eichbaum, B. R., Sandgren, K. R., Shanks, D. E. "Removal of Heavy Metals and Other Cations from Wastewater Using Zeolites", Separation Science and Technology, 25(13-15), pp. $1555-1569,1990$. https://doi.org/10.1080/01496399008050409

[14] Ramesh, A., Rama, M. K., Seshaiah, K., Venkateswarlu, C. N. "Removal of beryllium from aqueous solutions by zeolite 4A and bentonite", Separation Science and Technology, 37(5), pp. 1123-1134, 2002. https://doi.org/10.1081/SS-120002245

[15] Ashrafi, S. D., Kamani, H., Mahvi, A. H. "The optimization study of direct red 81 and methylene blue adsorption on $\mathrm{NaOH}$-modified rice husk", Desalination and Water Treatment, 57(2), pp. 738-746, 2016. https://doi.org/10.1080/19443994.2014.979329

[16] Kumar, A., Prasad, B., Mishra, I. M. "Optimization of process parameters for acrylonitrile removal by a low-cost adsorbent using Box-Behnken design", Journal of Hazardous Materials, 150(1), pp. 174-182, 2008. https://doi.org/10.1016/j.jhazmat.2007.09.043

[17] Tan, J., Wei, X., Ouyang, Y., Fan, J., Liu, R. "Adsorption Properties of Copper (II) Ion From Aqueous Solution by Starch-Grafted Polyacrylamide and Crosslinked Starch-Grafted Polyacrylamide", Periodica Polytechnica Chemical Engineering, 58(2), pp. 131-139, 2014.

https://doi.org/10.3311/PPch.7185

[18] Huang, M., Xu, C., Wu, Z., Huang, Y., Lin, J., Wu, J. "Photocatalytic discolorization of methyl orange solution by $\mathrm{Pt}$ modified $\mathrm{TiO}_{2}$ loaded on natural zeolite", Dyes and Pigments, 77(2), pp. 327-334, 2008. https://doi.org/10.1016/j.dyepig.2007.01.026

[19] Buzetzky, D., Nagy, N. M., Kónya, J. "Use of La-, Ce-, Y-, Febentonites for Removing Phosphate Ions from Aqueous Media", Periodica Polytechnica Chemical Engineering, 61(1), pp. 27-32, 2017.

https://doi.org/10.3311/PPch.9871

[20] Ates, A., Akgül, G. "Modification of natural zeolite with $\mathrm{NaOH}$ for removal of manganese in drinking water", Powder Technology, 287, pp. 285-291, 2016.

https://doi.org/10.1016/j.powtec.2015.10.021
[21] Ates, A., Hardacre, C. "The effect of various treatment conditions on natural zeolites: Ion exchange, acidic, thermal and steam treatments", Journal of Colloid and Interface Science, 372(1), pp. 130-140, 2012. https://doi.org/10.1016/j.jcis.2012.01.017

[22] Mihaly-Cozmuta, L., Mihaly-Cozmuta, A., Peter, A., Nicula, C., Tutu, H., Silipas, D., Indrea, E. "Adsorption of heavy metal cations by Na-Clinoptilolite: Equilibrium and selectivity studies", Journal of Environmental Management, 137, pp. 69-80, 2014. https://doi.org/10.1016/j.jenvman.2014.02.007

[23] Xu, D., Li, L. X., Li, X. Q.,Liu, W. C., Jia, Y. "Excellent fluoride removal properties of porous hollow $\mathrm{MgO}$ microspheres", New Journal of Chemistry, 38(11), pp. 5445-5452, 2014. https://doi.org/10.1039/C4NJ01361A

[24] Lin, H., Liu, Q., Dong, Y., He, Y., Wang, L. "Physicochemical properties and mechanism study of clinoptilolite modified by $\mathrm{NaOH}$ ", Microporous and Mesoporous Materials, 218, pp. 174-179, 2015. https://doi.org/10.1016/j.micromeso.2015.07.017

[25] He, K., Chen, Y., Tang, Z., Hu, Y. "Removal of heavy metal ions from aqueous solution by zeolite synthesized from fly ash", Environmental Science and Pollution Research, 23(3), pp. 2778-2788, 2016. https://doi.org/10.1007/s11356-015-5422-6

[26] Sadeghalvad, B., Torabzadehkashi, M., Azadmehr, A. R. "A comparative study of $\mathrm{Cu}(\mathrm{II})$ and $\mathrm{Pb}$ (II) adsorption by Iranian bentonite (Birjand area) in aqueous solutions", Advances in Environmental Technology, 1(2), pp. 93-100, 2015. https://doi.org/10.22104/aet.2015.186

[27] Salem, A., Akbari Sene, R. "Removal of lead from solution by combination of natural zeolite-kaolin-bentonite as a new low-cost adsorbent", Chemical Engineering Journal, 174(2-3), pp. 619-628, 2011.

https://doi.org/10.1016/j.cej.2011.09.075

[28] El-Mekkawi, D., Selim, M. M. "Removal of $\mathrm{Pb}^{2+}$ from water by using Na-Y zeolites prepared from Egyptian kaolins collected from different sources", Journal of Environmental Chemical Engineering, 2(1), pp. 723-730, 2014. https://doi.org/10.1016/j.jece.2013.11.014

[29] Katsou, E., Malamis, S., Tzanoudaki, M., Haralambous, K. J. Loizidou, M. "Regeneration of natural zeolite polluted by lead and zinc in wastewater treatment systems", Journal of Hazardous Materials, 189(3), pp. 773-786, 2011. https://doi.org/10.1016/j.jhazmat.2010.12.061 